\title{
Finansal Kiralama İşlemlerinin Vergi Usul Kanunu ile Büyük ve Orta Boy İşletmeler( BOBİ) Açısından Karşılaştırılması Üzerine Bir Değerlendirme
}

DOI: 10.26466/opus.568710

\author{
* \\ $\underline{\text { Murat Karahan* }}$ \\ * Dr.Öğr.Üyesi, Gaziantep Üniversitesi İ̈BF, İşletme Bölümü, Gaziantep/Türkiye \\ E-Posta: karahan@gantep.edu.tr \\ ORCID: 0000-0002-5066-4257
}

Öz

Günümüzde alternatif finansman kaynaklarına eğilim gün geçtikçe gelişmekte olan ekonomilerdeki işletmeler için önem arz etmektedir. İşletmelerin finansman kaynağı olarak tercih ettiği yöntemlerden biri olan, dünyada uzun zamandan beri ve ülkemizde yerleşik olarak kullanılan finansal kiralamadır. Türkiye Muhasebe Standard 17 (TMS 17 Kiralama İşlemleri Standardı) göre finansal kiralama; Bir varlığın mülkiyetine sahip olmaktan kaynaklanan her türlü risk ve yararların devredildiğgi sözleşmedir. Hukuki düzenlemelerde değiş̧ikliklerin süreklilik arz etmesi, finansal kiralama işlemlerinde hem kiraya veren hem de kiracı yönünden değişikliklere neden olmuştur. Bu kapsamda çalışmanın amacı, Büyük ve Orta Boy Işsletmelerde finansal kiralama açısından son yıllarda gerçekleştirilen mevzuat değişikliklerinin özellikle Vergi Usul Kanunu (VUK), Büyük ve Orta Boy İşletmeler için Finansal Raporlama Standardının (BOBİ FRS) kapsamında karşılaştırılmalı bir teorik çalışma yaparak,finansal kiralama işlemlerinin VUK ve BOBI FRS'ye göre taraflar açıcından benzerlikleri ve farkllikları tespit etmektir. Çalışmada finansal kiralama işlemleri ile ilgili Vergi Usul Kanunu ve BOBI FRS arasindaki kiralayan ve kiracı açısından benzerlikler ile farklılıklar irdelenmiştir ve tablolar halinde belirtilmiştir. Kiralama işlemi yapıldığında, kiracının maddi duran varlıklara mı yoksa maddi olmayan duran varlı̆̆ın mı kaydedeceği konusu ortaya çıkarılan farklılıklardan biridir.

Anahtar Kelimeler: $\quad$ Finansal Kiralama, Vergi Usul Kanunu, Kiralama İşlemleri Standardı 


\title{
An Assessment on the Comparison of Financial Leasing with The Tax Procedural Law and The Financial Reporting Standards for Large and Medium-Sized Enterprises
}

\begin{abstract}
Today, the tendency to alternative sources of financing is important for enterprises in increasingly emerging economies. One of the preferred methods of finance as a source of enterprises is financial leasing which has been used in the world for a long time and settled in our country. In accordance with Turkey Accounting Standard 17 (IAS 17 Leases Standard) by leasing; It is the contract to which all the risks and benefits arising from owning an asset are transferred. The continuity of the changes in the legal regulations has caused changes in terms of both the lessor and the tenant in the financial leasing transactions. In this context, the aim of this study is to make a comparative study on the legislative changes made in recent years in terms of financial leasing in Large and Medium-sized Enterprises, especially in the Tax Procedure Law (TPL), Financial Reporting Standard for Large and Medium-Sized Enterprises (LMS FRS), and LMS FRS to identify similarities and differences from the parties opener. In this study, the similarities and differences between the Tax Procedures Law and BOBI FRS regarding leasing and tenants are examined and stated in tables. When leasing is performed, it is one of the differences that reveal whether the lessee will record tangible assets or intangible assets.
\end{abstract}

Keywords: Financial Leasing, Tax Procedure Law, Leasing Operations Standard 


\section{Giriş}

Türkiye'de, Finansal kiralama, Büyük ve Orta Boy işletmelerin, işletme faaliyetlerini yürütmeleri için gerekli olan finansmanı sağlamalarına yönelik yöntemlerden biridir ve her geçen yıl artmaktadır. Bundan dolayıdır ki, finansal kiralama mevzusu mükellefler tarafından daha iyi araştırılmalıdır. Bununla beraber finansanl kiralamanın bütün olumlu ve olumsuz yönlerinin tespit edilmesi, işletmelerin karlarının en üst seviyeye çıkarmaları amacı açısından önemli hale gelmektedir (Doldur, 2018).

Finansal kiralamanın geçmişi M.Ö. 2000'li yıllara kadar gitmektedir, sonrasinda ise Finansal Kiralama "Leasing", Amerika Birleşik Devletlerinde 1930'lu yıllarda, Avrupa'da ise 1960'l yıllarda işletmeler tarafından kullanılmaya başlanmıştır. Finansal kiralamanın Türkiye'deki geçmişi ise 1983 yılına dayanmaktadır (Kırlığlu ve Öztaş, 2015).

Avrupa Leasing Birliği'ne göre "Finansal Kiralama, belirli bir süre için, üreticiden kiracı tarafından seçilip kiralayan tarafından satın altnan taşınır veya taşınmazın mülkiyet hakkını kiralayanda, kullanım hakkını ise kiracıda bırakan bir anlaşma" olarak tanımlamaktadır. Finansal kiralama, 6361 sayılı Finansal Kiralama, Faktoring ve Finansman Şirketleri Kanunu'na göre ise, "sözleşmeye dayal olmak şartıyla, kanun veya ilgili mevzuat gereği yetkilendirilen kiralayan tarafindan finansman elde etmek amacryla bir malın mülkiyetinin kira süresi sonunda kiractya devredilmesi; kiracıya kira süresi sonunda malın rayiç bedeli üzerinden düşük bir bedelle satın alma hakk tanınması; kiralama süresinin malın ekonomikömrünün yüzde sekseninden daha büyük bir bölümünü kapsaması veya finansal kiralama sözleşmesine göre yapılacak kira ödemelerinin bugünkü değerlerinin toplamının malın rayiç bedelinin yüzde doksanından daha büyük bir değeri oluşturması hâllerinden herhangi birini sağlayan kiralama işlemi" olarak tanımlanabilmektedir.

Kiralama işlemleri faaliyet kiralaması ve finansal kiralama olarak gruplandırılmıştır. Bu durumdan ötürü muhasebe yaklaşımlarının farklı olması, bir finansal olayın farklı şekillerde muhasebeleştirilmesine ve raporlanmasına dolayısıyla kiralama işlemlerinin finansal tablolarda güvenilir olarak gösterilmemesine neden olmaktadır. Neticede finansal tablo kullanıcıları anlaşılır, güvenilir, karşılaştırılabilir ve ihtiyaca uygun şe- 
kilde bilgi alamamaktadırlar. Standart belirleyicileri ise yaşanılan bu durumları engellemek için, kiralamanın muhasebeleştirilmesinin geliştirilmesi adına bazı çalışmalar yapmışlardır (Cengiz, 2017).

Günümüz koşullarının uluslararası bir boyut kazanması ile; finansal piyasalardaki gelişim, çok uluslu şirket sayısındaki artış, uluslararası boyut kazanan firmaların farklı ülkelerde farklı uygulamalardan dolayı karşılaştıkları sıkıntıların bertaraf edilmesi ve finansal tablolardaki şeffaflık ve karşılaştırılabilirliği elde edilmesi amacıyla Uluslararası Finansal Raporlama Standartları (UFRS) ülkemizde de uygulanmaya konulmuştur. Kamu Gözetimi Muhasebe ve Denetim Standartları Kurumu (KGK), bu standartları yayınlamaya yetkili olan tek kurumdur. Yayınlanan standartlar ile birlikte, vergi kanunları ile muhasebe uygulamaları arasındaki uyuşmazlıklar finansal kiralama işlemlerinde de ortaya çıkmaktadır (Gönen ve Akça, 2014).

$\mathrm{Bu}$ çalışmada, Büyük ve Orta Boy İşletmelerde finansal kiralama açısından son yıllarda gerçekleştirilen mevzuat değişikliklerinin özellikle Vergi Usul Kanunu (VUK), Büyük ve Orta Boy İşletmeler için Finansal Raporlama Standardının (BOBİ FRS) kapsamında karşılaştırılmalı bir teorik çalışma yaparak, finansal kiralama işlemlerinin VUK ve BOBİ FRS'ye göre taraflar açısından benzerlikleri ve farklılıkları açıklanmaya çalışılmıştır.

\section{Literatür İncelemesi}

Gökgöz (2013), Gönen ve Akça (2014), Köksal ve Beller (2013), Yakut (2016) çalışmalarında finansal kiralama işlemlerini TMS 17 ve VUK'nu hükümleri incelenerek MSUGT ve BBDK hesap planları doğrultusunda kiracı ve kiraya veren yönünden muhasebe uygulamaları yapılmıştır.

Kırlıŏlu ve Öztaş (2013) çalışmalarında finansal kiralama işlemlerini TMS 17 ve VUK'nu hükümleri incelenerek MSUGT ve BBDK hesap planları doğrultusunda kiracı ve kiraya veren yönünden TMS 17 ye göre muhasebe uygulamaları yapılmıştır.

Şengür (2013) çalışmasında finansal kiralama işlemlerini TMS 17 ve VUK'nu hükümleri incelenerek kiracı yönünden asgari kira ödemelerinin hesaplanması ve finansal raporlamaya etkileri ne yönelik örnek uygulamalar yapılmıştır. 
Şenyigit (2014), Öztürk (2016), Aslan (2018), Maşrap ve Yanık (2018), çalışmalarında finansal kiralamada kiracı yönünden UMS 17 ve UFRS 16 karşılaştırılması yapılarak, yeni düzenlemenin finansal raporlamalar üzerinden, finansal oranlara etkisi değerlendirilmiştir.

Yıldız, Kara ve Yanık (2014) çalışmalarında Kobi TFRS ye göre kiralama işlemlerini örnek muhasebe uygulamaları yapılarak TFRS ile farkları incelenmiştir.

Öztaş ve Burak (2014) çalışmalarında uluslararası ticarette finansal kiralama işlemlerini TMS 17 ve VUK'nuhükümleri incelenerek BBDK hesap planları doğrultusunda kiraya veren yönünden TMS 17 ye göre muhasebe uygulamaları yapılmıştır.

Duman, Polat ve Yucenursen (2015) çalışmalarında finansal ve faaliyet kiralamalarının TMS 17 ye göre örnek uygulama üzerinden finansal tablo ve oranları üzerindeki etkisi araştıılmıştır.

Yardımcıoğlu (2016) çalışmasında finansal kiralama işlemlerinin islami muhasebe standartları çerçevesinde TMS 17 ile FAS 8 karşılaştırmaları yapılarak kiraya veren yönünden kayıtlar incelenmiştir.

Şentürk (2016) çalışmasında faaliyet kiralama işlemlerini vergi mevzuatı kapsamında kiracı ve kiraya veren yönünden örnek muhasebe uygulamaları yapılmıştır.

Acar, Temiz ve Aktaş (2017) çalışmalarında BİST'te işlem gören bazı sektörlerdeki finansal verileriden faydalanılarak UMS 17 den UFRS 16 ya geçiş sonucu geleneksel kiralamalarda kiracı yönünden aktifleştirmenin etkisi t-test analizi yapılarak farklılıklar tespit edilmeye çalışmışlardır.

Cengiz (2017) çalışmasında Finansal kiralama işlemleriniTMS 17 ve VUK yönünden karşılaştırmalar yapılarak kiracı ve kiraya veren yönünden örnek muhasebe kayıtları yapılmıştır.

Akbulut (2018) çalışmasında BİST'te işlem gören telekomünikasyon sektöründe faaliyet gösteren firmanın belli bir tarihteki finansal verilerinden yola çıkarak UMS 17 den UFRS 16 ya geçişin mali tablolardaki değişimi incelenmiştir.

Demirci ve Kıymaz Kıvraklar (2018) çalışmalarında Ulusal ve Uluslararası düzenlemeler çerçevesinde (TMS 17, UFRS 16, BOBİ FRS 15 ve VUK) kiracı ve kirayalayan yönünden finansal kiralama işlemlerinin genel olarak karşılaştırılması ve örnek muhasebe kayıtları ile farklılıkları tespit edilmeye çalışılmıştır. 
Doldur (2018) çalışmasında finansal kiralama işlemlerinin TMS 17 ve VUK'nundaki uygulamalarından bahsedilerek VUK'a uygun muhasebe kayıtları ile örnek çalışma yapılmış olup bazı özellikli konulara değinilmiştir.

Şeker ve Çemberlitaş (2018) çalışmalarında finansal kiralama işlemlerini TMS 17 ve VUK'nu hükümleri incelenerek kiracı ve kiraya veren yönünden TMS 17 ye göre muhasebe uygulamaları yapılmıştır.

\section{Finansal Kiralama}

Finansal kiralama işletmelerin faaliyetlerini yürütebilmeleri amacıyla gerekli olan sermayeye ulaşabilme yöntemlerinden biridir. Finansal kiralama, varlığa ait mülkiyetin kiralayan tarafında, varlığın kullanım hakkı ise kiracıda olacak şekilde yapılan bir yatırım aracı olarak tanımlanabilmektedir. Bu yöntemde kiracı kiralanan malın ekonomik ömrünün büyük bir kısmını kullanma yetkisini elde etmekte ve mülkiyet dışındaki bütün riskleri ve faydaları üstlenmektedir (Yakut, 2016).

Finansal kiralamanın birden fazla tanımı bulunmaktadır. Bu tanımlardan biri "Finansal kiralama, kiraya verenin kiracıya bir dizi ödemeyi ödemesini taahhüt eden ve kiralanan varlığın satın alma bedelini aşan toplam değerlerden vazgeçtiği sözleşmeli bir düzenlemedir" (Wyman, 1973).

Farklı bir tanımda ise Finansal Kiralama şu şekilde geçmektedir; "Kiralama, genelde herhangi bir varlığın iktisaden kullanım hakkını mülkiyetini devralmadan, belirlenen bir süre için gerçekleştirmek anlamında, özelde firmalar açısından orta ve uzun vadeli (en az dört yıllık) nakit gereksinimleri karşılayan bir finansman kaynağı olarak görülen bir yöntemdir. Leasing yöntemi; finansal kiralama firması yatırım malının mülkiyetini kendisinde tutarak, sözleşmeyle belirlenen kiralar karşılığında, kullanım hakkının kiracıya verilmesi ve sözleşmede belirlenen satın alma opsiyonu (tercih hakkı) üzerinden, sözleşme süresi sonunda mülkiyetin kiracıya geçmesini düzenleyen finansman aracıdır" (Şişman ve Şişman, 2017).

Avrupa Leasing Şirketleri Derneği Federasyonu'na göre finansal kiralama tanımı ise; "kiracının kiracıya, bir ödeme veya dizi ödeme karşılığında, kararlaştırılan bir süre için bir varlık kullanma hakkını ilettiği bir anlaşma" şeklindedir. 
Ülkemizde Finansan Kiralamanın tanımı 2012 tarihinde yayınlanan 6361 Sayılı Finansal Kiralama, Faktoring ve Finansman Şirketleri Kanunu'nda şöyle tanımlanmaktadır;

“Bir finansal kiralama sözleşmesine dayal olmak koşuluyla, bu Kanun veya ilgili mevzuatı uyarınca yetkilendirilen kiralayan tarafından finansman sağlamayayönelik olarak bir malın mülkiyetinin kira süresi sonunda kiractya devredilmesi; kiracıya kira süresi sonunda malın rayiç bedelinden düşük bir bedelle satın alma hakkı tanınmasi; kiralama süresinin malın ekonomik ömrünün yüzde sekseninden daha büyük bir bölümünü kapsaması veya finansal kiralama sözleşmesine göre yapılacak kira ödemelerinin bugünkü değgerlerinin toplamının malın rayiç bedelinin yüzde doksanından daha büyük bir değeri oluşturması hâllerinden herhangibirini sağlayan kiralama işlemidir"

Karapınar ve Eflatun (2018), "Büyük ve Orta Boy İşletmeler İçin Finansal Raporlama Standardı Uygulamalar ve Yorumları" kitabında finansal kiralama için şu şekilde ifade kullanmışlardır; "Kiralama sözleşmeleri, kiraya konu olan varlığın sahipliğine ilişkin risk ve getirilerin verende kalması veya kiracıda bulunması derecesine göre sinıflandırılır". Bir varlıkla ilgili riskler, ekolojik değişiklikler nedeniyle demode olması, varlığın atıl kalması ve ekonomideki değişiklikler gibi nedenlerle getirinin değişmesi durumudur. Varlığın değerinin artması veya kalıntı değerinin artması, varlığın yararlı ömrü içinde karlı bir şekilde işletilmesi gibi nedenler isevarlık ile ilgili getirileri oluşturmaktadır. Finansal kiralama, kiralama konusu varlıkların mülkiyetine ilişkin risk ve getirilerin tamamının kiracıya devredildiği kiralama işlemleridir.

\section{Finansal Kiralama İşlemlerinin Mevzuat Bakımından Değer- lendirilmesi}

Ülkemizde finansal kiralama ilk olarak, 70 sayılı bankalar hakkında kanun hükmünde kararnamenin 90. Maddesine istinaden çıarılan 16.12.1983 tarih ve 83/7506 sayılı bankalar kurulu kararında yapılmış olup gerçek anlamda ise hukuki altyapıya 28.06.1985 tarih ve 18795 sayılı Resmi Gazete'de yayımlanan 3226 sayılı Finansal Kiralama Kanunu ile kavuşmuştur.

Finansal kiralama kanunun yetersiz kalması üzerine, 13.12.2012 tarih ve 28496 sayılı Resmi Gazate' de yayımlanan 6361 sayılı “Finansal Kiralama, 
Faktoring ve Finansman Şirketleri Kanunu" ile 3226 sayılı Kanun ve 90 sayılı Kanun Hükmünde Kararname ek ve değişiklikleri yürürlükten kaldırılmıştır. İlgili 6361 sayılı kanunun 14 üncü ve 16 ncı maddelerine dayanılarak, 24.12.2013 tarih ve 28861 sayılı Resmi Gazete'de yayımlanan "Finansal Kiralama, Faktoring ve Finansman Şirketlerince uygulanacak Tekdüzen Hesap Planı ve İzahnamesi Hakkında Teblĭg" ile "Finansal Kiralama, Faktoring ve Finansman Şirketlerinin Muhasebe Uygulamalarn ile Finansal Tabloları Hakkında Yönetmelik" yayımlanarak yürürlüğe girmiştir. Finansal kiralama şirketleri son bu yasal düzenlemeler çerçevesinde Kamu Gözetimi, Muhasebe ve Denetim Standartları Kurulu tarafından belirlenen usul ve esaslar göre muhasebe kayıtlarını ve finansal raporlamaları düzenleme yükümlülükleri getirilmiştir.

Finansal Kiralama şirketlerine bağımsız denetim yükümlüğü 23.01.2013 tarih ve 28537 sayılı Resmi Gazete'de yayımlanan 2012/4213 sayılı Bakanlar Kurula Kararı ile kapsamına alınmış ve 26.08.2014 tarih ve 29100 sayılı Resmi Gazete' de yayımlanan Kamu Gözetimi, Muhasebe ve Denetim Standartları Kurumunun 75935942-050.01.04-[01/26] sayılı kararı ile 01.01.2014 tarihi ve sonrasından itibaren başlayan hesap dönemlerinde Finansal tabloların hazırlanmasında Türkiye Muhasebe Standartlarına uygulama zorunluluğu getirilmiştir. İlgili Kurul Kararı sebebiye TFRS uygulamayan Bağımsız denetime tabi işletmelerin münferit ve konsolide finansal tablolarının hazırlanmasında uygulanmak üzere; 29 Temmuz 2017 tarihli ve 30138 Sayılı Mükerrer Resmi Gazete'de yayımlanan "Büyük ve Orta Boy Isşletmeler İçin Finansal Raporlama Standardı Hakkında Tebliğ" ve eki yayımlanmıştır. Bu tebliğin ekinde 15. Bölümünde Kiralamalar ile ilgili bölüm yer almakta olup Finansal Kiralama şirketleri kiraya veren yönünden finansal tablolarının hazırlanmasında TMS 17 / TFRS 16 uygulamalarını kullanması gerekeceğinden BOBI FRS yi kullanmayacaklardır. Dolayısıyla ilgili örnek uygulamada sadece kiracı yönünden incelenecektir.

Finansal kiralama uygulamalarına ilişkin mevcut muhasebe sistemini vergi yasaları ile uyumlu hale getirmek için 2003 yılında çıkartılan 4842 sayılı Kanunun 25. maddesiyle Vergi Usul Kanunu'na "Finansal Kiralama İşlemlerinde Değerleme" başlığıyla mükerrer 290. madde eklenmiştir. Söz konusu bu maddeye istinaden 319 seri no.lu VUK Genel Tebliği ile 11 sira no.lu Muhasebe Sistemi Uygulama Genel Tebliği yayınlanmıştır. 


\subsection{VUK açısından Finansal Kiralama}

2003 yılında çıkartılan 4842 sayılı kanunun 25. maddesiyle Vergi Usul Kanunu'na "Finansal Kiralama İşlemlerinde Değerleme" başlığıyla mükerrer 290. Maddesinde kiralayan ve kiraya verene dair bilgiler bulunmaktadır. Bu maddenin uygulamasında aşağıda yer alan tanımlar dikkate alınır.

Finansal Kiralamanın şu şeklinde tanımlanmıştır:

"Kira süresi sonunda mülkiyet hakkının kiractya devredilip devredilmediğine bakılmaksızın, bir iktisadî kıymetin mülkiyetine sahip olmaktan kaynaklanan tüm riskler ile yararların kiracıya bırakılması sonucunu doğuran kiralamalardır."

Bu tanımlamaya ek olarak şu ifadeler kullanılmıştır:

"Kiralama işleminde; iktisadî kıymetin mülkiyetinin kira süresi sonunda kiracıya devredilmesi, kiracıya kira süresi sonunda iktisadî kıymeti rayiç bedelinden düşük bir bedelle satın alma hakkı tanınması, kiralama süresinin iktisadî kıymetin ekonomik ömrünün \% 80'inden daha büyük bir bölümünü kapsaması veya sözleşmeye göre yapılacak kira ödemelerinin bugünkü değerlerinin toplamının iktisadî kıymetin rayiç bedelinin \% 90'ından daha büyük bir değeri oluşturması hallerinden herhangi birinin varlığı durumunda kiralama işlemi finansal kiralama kabul edilir."

Gelir İdaresi Başkanlığının 02.03.2018 tarih ve B.07.1.GİB.4.34.19.02105[290-2015/VUK1-18995]-213349 özelgesinde 6361 sayılı kanun ile kurulan Finansal Kiralama şirketi olmamasına rağmen yapılan faaliyetin VUK'nu hükümlerine göre finansal kiralama sayılabileceği belirtilmektedir.

Ayrıca hangi durumların finansal kiralama kapsamına dahil olacağı ise "Arsa, arazi ve binalarla ilgili kiralama sözleşmeleri, sadece, sözleşmede kira süresi sonunda mülkiyet hakkının kiracıya devri öngörülmüşse veya kiracıya kira süresi sonunda kiralama konusu gayrimenkulu düşük bir bedelle satın alma hakkı tanınmışsa bu madde kapsamında değerlendirilir" şeklinde belirtilmiştir.

İstisnai durumları belirtmek için ise "Doğal kaynakların araştırılması veya kullanılmasına yönelik kiralama sözleşmeleri ile sinema filmleri, video kayıtları, patentler, kopyalama hakları gibi kıymetlerle ilgili lisans sözleşmeleri bu madde kapsamında değerlendirilmez" denilmektedir. 
VUK'a göre Kira Ödemeleri: “Sözleşmeye göre, kira süresi boyunca yapılması gereken kira ödemeleridir. Buna ilaveten kira süresi sonunda, kiralama konusu iktisadî kıymetin kalan değerine ilişkin bir taahhüt olması halinde bu değer de kira ödemesi kabul edilir." denilmektedir.

Ayrıca "Kira süresi sonunda kiracıya düşük bir bedelle iktisadî kıymeti satın alma hakkı tanındığı ve sözleşme tarihinde bu hakkın kullanılma olasılığının yüksek olduğu durumda kira ödemeleri kira süresi boyunca yapılan kira ödemeleri ile satın alma hakkının kullanılması durumunda ödenmesi gereken bedelin toplamı$d \imath r^{\prime \prime}$ ibaresi bulunmaktadır

VUK'a göre Kira Ödemelerinin Bugünkü Değeri ise "Kira ödemelerinin, sözleşme tarihinde, kiralamada kullanılan faiz oranının dikkate alınması suretiyle hesaplanan bugünkü değerlerinin toplamıdır."

Bununla birlikte "Kiralamada kullanilan faiz oranı tespit edilemiyorsa, kiracının kiralamaya konu iktisadî kıymeti satın almak için aynı vade ile alması gereken borç için katlanacă̆ı faiz oranı kullanılır" denilmektedir.

VUK'a göre Kiralamada Kullanılan Faiz Oranı: "Kira ödemeleri ile garanti edilmemiş kalan değer toplamının bugünkü değerini, kiralamaya konu iktisadî kıymetin rayiç bedeline eşitleyen iskonto oranıdır."

VUK'a göre Finansal kiralama işlemlerinde kiracı ve kiralayan tarafından, finansal kiralamaya konu olan iktisadî kıymet ile sözleşmeden doğan hak, borç ve alacakların değerlemesi aşağıdaki esaslara göre yapılır.

\section{Kiracıya göre uygulanması gereken esaslar;}

- "Kiracı tarafindan finansal kiralama işlemine konu iktisadî kıymeti kullanma hakkı ve sözleşmeden doğan borç, kiralama konusu iktisadî kıymetin rayiç bedeli veya sözleşmeye göre yapılacak kira ödemelerinin bugünkü değerinden düşük olant ile değerlenir."

- "Kiracı tarafindan aktifleştirilen finansal kiralamaya konu iktisadî kıymeti kullanma hakkı, bu Kanunun mükerrer 298 inci maddesi ve üçüncü kitabının üçüncü kısmının birinci bölümünde kiralama konusu iktisadî kıymet için belirlenmiş esaslar çerçevesinde yeniden değerlemeye ve amortismana tâbi tutulur."

- "Kiracı tarafindan finansal kiralama sözleşmesine göre yapilan kira ödemeleri, borç anapara ödemesi ve faiz gideri olarak ayruştırılır. Ayrıştırma işlemi, her bir dönem sonunda kalan borç tutarma sabit bir dönemsel faiz oranı uy- 
gulanmasını să̆layacak şekilde yapılır. Ayrıca T.C. Kırşehir Valiliği Defterdarlı̆̆ııı 27.10.2011 tarihli özelgesine göre finansal kiralamaya konu olan varlığın ilk yıl için oluşan faiz giderleri ve kur farklarının maliyet olarak dikkate alınması sonraki yıllarda ise maliyet ya da gider olarak dikkate alınması gerekmektedir."

\section{Kiralayana göre uygulanması gereken esaslar;}

- "Kiralayan tarafindan sözleşmeden doğan alacak, kiralama süresi boyunca yapılacak kira ödemelerinin toplam tutarı, kiralama konusu iktisadî kıymet ise, bu iktisadî kıymetin net bilanço aktif değerinden kira ödemelerinin bugünkü değerinin düşülmesi sonucu bulunan tutar ile değerlenir."

- "Iiktisadi klymetin net bilanço aktif değerinden kira ödemelerinin bugünkü değerinin düşülmesi sonucu bulunan tutarın sıfır veya negatif olması halinde, iktisadî kuymet iz bedeliyle de ğerlenir ve aradaki fark iktisadî kıymetin elden çıkarılmasından elde edilen kazançlar gibi işleme tâbi tutulur."

- "Kiralayan tarafindan aktifleştirilen alacak tutarn ile kira ödemelerinin bugünkü değeri arasındaki fark, gelecek dönemlere ait faiz geliri olarak pasifleştirilmek suretiyle değerlenir."

- "Kiralayanın finansal kiralamaya konu iktisadî kıymetin üretimini veya alım satımını yapması halinde, iktisadî kıymetin net bilanço aktif değeri olarak rayiç bedeli dikkate alınır. Rayiç bedel ile maliyet bedeli arasındaki fark, normal bir satış işleminden elde edilen kâr veya zarar olarak işleme tâbi tutulur."

- "Kiralayan tarafindan, finansal kiralamaya konu iktisadî kıymetin bu maddenin (1) numaralı fikrasının üçüncü paragrafina göre belirlenen değeri üzerinden amortisman ayrlmaya devam olunur."

- "Bu madde kapsaminda değerlenen borç ve alacak tutarları reeskonta tâbi tutulmaz."

- "Kiralayan tarafindan gelecek dönemlere ait faiz gelirleri, kiralanan iktisadî kıymetin finansal kiralama sözleşmesinin yapıldığı tarihteki rayiç bedelinden, her bir dönem sonunda anapara geri ödemelerinin düşülmesi sonucu kalan tutar üzerinden sabit bir dönemsel faiz oranı yaratacak şekilde hesaplanması suretiyle tahakkuk ettirilir." 


\subsection{BOBİ FRS açısından Finansal Kiralama}

29 Temmuz 2017 tarihli ve 30138 Sayılı Mükerrer Resmi Gazete'de yayımlanan "Büyük ve Orta Boy İşletmeler İçin Finansal Raporlama Standardı Hakkında Tebliğ" ve eki "Büyük ve Orta Boy İşletmeler İçin Finansal Raporlama Standardı" nın 15. Bölümünde finansal kiralama ile ilgili ibareler verilmektedir.

Standart içerisinde kiralama işlemlerine ait tanımlar geçmektedir. Bu tanımlar;

"Kiralama, kiraya verenin bir varliğın kullanım hakkını, bir ödeme veya ödeme planı karşılığında, taraflarca kararlaştıılımış bir süre için kiracıya devrettiği sözleşmedir" şeklinde tanımlanmaktadır.

BOBİ FRS ye göre "Kiralama sözleşmesinin başlangıcı: Sözleşme tarihinden veya tarafların kiralamanın temel şartlarına ilişkin taahhütte bulundukları tarihten erken olanıdır."

Ayrica ilave olarak,

"Bu tarih itibarryla:

a) Kiralama işlemleri geleneksel kiralama veya finansal kiralama olarak siniflandirilir ve

b) İşlemin finansal kiralama olarak sinıflandırılması durumunda, kiralama süresinin başlangıcında kayda alınması gereken tutarlar belirlenir." denilmektedir.

BOBİ FRS'ye göre Kiralama süresinin başlangıcı: "Kiracının kiralamış

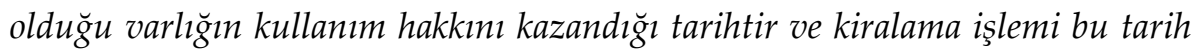
itibarıla kayda alını" denilmektedir.

BOBI FRS'ye göre Kira ödemeleri: "Sözleşmeye göre kiralama süresi boyunca kiracı tarafindan yapılması gereken ödemelerdir. Kiralama süresi sonunda ilgili varlı̆̆ın kalıntı değgrine ilişkin garanti edilmiş bir tutarın bulunması durumunda bu tutar da kira ödemeleri kapsamında değerlendirilir" denilmektedir.

BOBİ FRS'ye göre Kiracıya sözleşmeye konu varlığı: “Hakkın kullanılacağı tarihteki gerçeğe uygun değerinden daha düşük bir bedelle satın alma hakkı tanınması ve kiralama sözleşmesinin başlangıcında bu hakkm kullanılma olasılığııın yüksek olması durumunda, kira ödemeleri hakkın kullanılacă̆ı tarihe kadarki kira ödemeleri ile hakkm kullanılması sonucunda ödenecek satın alma fiyatının toplamıdır"denilmektedir. 
Ayrıca "Şarta bağh kiralar, hizmet maliyetleri ve kiraya veren tarafindan ödenen ve kiraya verene tazmin edilen vergiler kira ödemeleri içerisinde sayılmaz" şeklinde bir ibare bulunmaktadır.

BOBİ FRS'ye göre Kiralamadaki zımni faiz oranı: "Kiralama sözleşmesinin başlangıcında, kira ödemelerinin bugünkü değeri ile garanti edilmemiş kalıntı değerin bugünkü değerinin toplamını, kiralanan varlığın gerçeğe uygun değeri ile kiraya verenin başlangıçta katlandığı doğrudan maliyetlerin toplamına eşitleyen iskonto oranıdır" denilmektedir.

Bölüm 15 de Finansal Kiralama ise şu şekilde belirtilmiştir;

"Kira süresi sonunda mülkiyetin devredilip devredilmediğine bakılmaksızın, bir varlığın sahipliğinden kaynaklanan risk ve getirilerin tamamına yakınının devredildiği kiralamalar, finansal kiralama olarak simıflandırilır."

"Ayrıca aşağıdaki durumların bir veya birden fazlasını karşılayan kiralama işlemlerinde varlı̆̆ın sahipliğinden kaynaklanan risk ve getirilerin tamamına yakınının kiracıya devredildiği kabul edilir ve kiralama işlemi finansal kiralama olarak kayda alınır:"

a) "Varlı̆̆ın sahipliğinin kira süresi sonunda kiractya devredilecek olması."

b) "Kiracıya, sözleşmeye konu varlı̆̆ı, hakkın kullanılacağ̊ tarihteki gerçeğe uygun değgrinden daha düşük bir bedelle satın alma hakkı tanınması ve kiralama sözleşmesinin başlangıcında bu hakkın kullanılma olasıliğııın yüksek olmast."

c) “Kiralama süresinin varlığın ekonomik ömrünün \%80'inden daha büyük bir bölümünü kapsaması. Ekonomik ömür, bir varlığın ekonomik olarak kullanılabileceği süreyi ya da varlıktan elde edilmesi beklenen üretim veya kullanım miktarın ifade eder."

d) "Kiralama sözleşmesinin başlangıcı itibarılyla kira ödemelerinin bugünkü değerinin varlığın gerçeğe uygun değerinin \%90'ından daha büyük bir değgri oluşturması."

e) İlaveten aşağıdaki durumlar da tek başlarına ya da birlikte, bir kiralama işleminin finansal kiralama işlemi olduğunun göstergesi olabilir:

f) "Kiralanan varlığın, üzerinde büyük değişiklikler yapılmadığı sürece, sadece kiracı tarafindan kullanılabilecek özel bir yapıda olması."

g) "Kiracının kiralama işlemini feshedebilmesi durumunda, kiraya verenin fesih işleminden kaynaklanan zararlarının kiracı tarafindan karşılanması." 
h) "Kiraya verilen varlığın kalıntı de ğerindeki değgişimlerden kaynaklanan kazanç veya kayıpların kiracrya ait olması."

i) "Kiracının, piyasa fiyatının çok daha altında bir kira bedeli ile belirli bir süre daha kiralamayı sürdürme hakkının bulunması."

Arazi, arsa ve binalarla ilgili kiralama sözleşmeleri sadece, aşağıdaki durumlardan birinin mevcut olması halinde finansal kiralama olarak kabul edilir:

a) "Kira süresi sonunda sahipliğin kiractya devredilecek olması."

b) "Kiracıya, sözleşmeye konu gayrimenkulü, hakkın kullanılacă̆ı tarihteki gerçeğge uygun de ğerinden daha düşük bir bedelle satın alma hakkı tanınması ve kiralama sözleşmesinin başlangıcında bu hakkın kullanılma olastlı̆̆ının yüksek olması."

Finansal Kiralama işlemlerinde ise Kiralama İşlemlerinin Kiracı Tarafından Kayda Alınması ve Ölçümü Standarda göre aşağıdaki şekilde yapilmalıdir;

- "Kiracı, kiralama süresinin başlangıcında, finansal kiralamaya konu varliğı ve sözleşmeden kaynaklanan yükümlülüğ̈̈nü, kiralanan varlığın gerçeğe uygun değeri ya da kira ödemelerinin bugünkü değerinden düşük olanı üzerinden kayda alır. Söz konusu iki değer de kiralama sözleşmesinin başlangıç tarihi itibarnla belirlenir."

- "Finansal kiralamaya konu varlik, türüne göre Finansal Durum Tablosunda ilgili kalem içerisinde gösterilir. Örneğin kiralamaya konu varliğın bina olması durumunda söz konusu varlık Finansal Durum Tablosunda Binalar-kalemi içinde yer alır."

- "Kira ödemelerinin bugünkü değeri, finansal kiralamada zımni faiz oranı kullanılarak hesaplanır. Söz konusu oranın belirlenememesi durumunda, kiraclnın kiralama konusu varlığı satın almış olsaydı kiralama sözleşmesinin başlangıç tarihi itibarıla benzer vade ve teminatlar çerçevesinde borçlanacak olduğu tutar için katlanması gereken faiz oranı kullanılır."

- "Kiracının katlandığı, başlangıçtaki doğrudan maliyetler varlık olarak muhasebeleştirilen tutara eklenir."

- "Kira ödemeleri ilk kayda almadan sonra finansman giderleri ve borç anapara ödemesi olarak ayrıştırılır. Finansman giderleri kalan borç tutarına sabit bir faiz oranı uygulanmasını sağlayacak şekilde kiralama süresi boyunca her bir döneme dağıtılır. Şarta bağlı kira ödemeleri ise oluştukları dönemde kâr veya zarara yansitılır." 
- “Kiracı finansal kiralamaya konu varlı̆̆a dönem sonlarnnda, türüne görebuvarlığınkapsamına girdiği bölümde (örneğin Maddi Duran Varliklar, Maddi Olmayan Duran Varlıklar ya da Yatırım Amaçlı Gayrimenkuller bölümü) yer alan ölçüm hükümlerini uygular. Bu kapsamda finansal kiralamaya konu varlğ̆ın uygulanan bölüme göre amortismana veya itfaya tâbi tutulması gerekiyorsa amortisman tutarı veya itfa payı hesaplanır. Bu durumda, kiracının kiralama süresi sonunda varlığın sahipliğini elde edeceğgine dair bir kesinlik yoksailgili varlık kiralama süresi veya faydalı ömürden kısa olanı itibarıla amortismana veya itfaya tâbi tutulur. Ayrıca,varliğın kapsamına girdiği bölüm gerektiriyorsa, kiralamaya konu varlğ̆ın değer düşük-

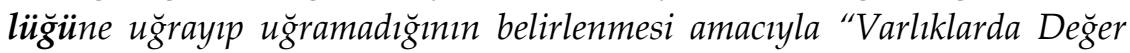
Düşüklüğ̈̈"bölümü hükümleri uygulanır."

Finansal Kiralama işlemlerinde ise Kiralama İşlemlerinin Kiraya Veren Tarafından Kayda Alınması ve Ölçümü Standarda göre aşağıdaki şekilde yapılmalıdır;

- "Kiraya veren finansal kiralamaya konu varlığını finansal tablo dışı bırakır. Varlığın gerçeğe uygun değeri ile başlangıçtaki doğrudan maliyetlerin toplamına eşit bir tutarda alacak kaydeder. Varlığın gerçeğe uygun değeri ile defter değeri arasindaki fark kâr veya zarara yansitıllır."

- "Alinan kira ödemeleri ilk kayda almadan sonra finansman gelirleri ve anapara geri ödemesi olarak ayrıştırılır. Finansman gelirleri kalan alacak tutarına sabit bir dönemsel getiri oranmı (diğger bir ifadeyle kiralamadaki zımni faiz oranını) yansıtan bir esasa göre kayda alınır. Şarta bağlı kira ödemeleri ise oluştukları dönemde kâr veya zarara yansitılır."

\section{Üretici veya Satıcı Niteliğindeki Kiraya Verenler ise;}

- "Üretici veya satıci niteliğindeki kiraya veren, finansal kiralama işlemlerini normal satış işlemi gibi kaydeder."

- "Üretici veya satıci konumundaki kiraya veren, kiralama süresinin başlangıcında kayda alacağı hasılat tutarını varlığın gerçeğe uygun değeri veya kira ödemelerinin piyasa faiz oranıyla indirgenmiş bugünkü değerinden düşük olanı üzerinden hesaplar."

- "Kiralama süresinin başlangıcında kayda alacağı satılan malın maliyeti tutarn ise varlı̆̆m defter değerinden garanti edilmemiş kalıntı değerin bugünkü değeri çıkarılarak bulunur." 
- "Satış hasılatı ile satışların maliyeti arasındaki fark, işletmenin normal bir satış işleminden elde edilen kâr veya zarar olarak Brüt Kâr/Zarar içinde yer alır."

- "Üretici veya satıcı niteliğindeki kiraya verenler başlangıçtaki doğrudan maliyetlerigider olarak kâr veya zarara yansitır."

- "Finansal kiralama işleminde gerçekçi olamayacak derecede düşük faiz oranları belirlenmişse, satış kârı, piyasa faiz oranının uygulanması sonucunda bulunacak tutarla sinurlandırılır."

\subsection{Finansal Kiralama İşlemlerininin BOBİ FRS ile VUK Açısından Karşılaştırılması}

Bu bölümde finansal kiralama işlemleri hem kiracı hem de kiraya veren açısından, BOBİ FRS'ye ve VUK'a göre karşılaştırılmıştır. Finansal kiralama işlemlerinin genel karşılaştırılması Tablo 1 de yapılmıştır. Tablo 2 de ise finansal kiralama işlemleri kiraya veren açısından karşılaştırılmış, Tablo 3 te ise finansal kiralama işlemleri kiracı açısından karşılaştırılmıştır (Demirci veKıymaz Kıvraklar, 2018).

Tablo 1. Finansal kiralama işlemlerinin genel karşılaştırılması

\begin{tabular}{|l|l|l|}
\hline $\begin{array}{l}\text { Finansal Kiralama - Faaliyet Kiralaması } \\
\text { Ayrımı }\end{array}$ & YUK & YOBİ FRS \\
\hline $\begin{array}{l}\text { Faaliyet Kiralaması Nerede kaydedile- } \\
\text { cek }\end{array}$ & - & - \\
\hline $\begin{array}{l}\text { Sözleşmede Sonradan Yapılacak deği- } \\
\text { şiklikler ile ilgili düzenleme }\end{array}$ & - & - \\
\hline Başlangıçtaki doğrudan maliyetler & $\begin{array}{l}\text { Dönem gideri ola- } \\
\text { rak yazılır }\end{array}$ & $\begin{array}{l}\text { Başlangıçtaki doğrudan mali- } \\
\text { yetler, maliyete eklenir }\end{array}$ \\
\hline
\end{tabular}

\subsubsection{Kiraya Verene göre Finansal Kiralama İşlemlerininin BOBİ FRS ile VUK Açısından Karşılaştırılması}

Tablo 2. Kiraya Veren Açısından Finansal Kiralama İşlemleri

\begin{tabular}{|l|l|l|}
\hline & VUK & BOBİ FRS \\
\hline \multirow{3}{*}{ İlk Ölçüm } & "Kiralama süresi boyunca kiracı tarafın- & "Varlık finansal tablo dışı bırakılır. \\
& dan yapılacak kira ödemelerinin toplam & Varlığın Gerçeğe Uygun Değeri ile başlangıç- \\
& tutarı, anapara artı faiz, alacak olarak & taki doğrudan maliyetler toplamı kira alacağı \\
& aktife alınacaktır. Diğer yandan, gelecek & olarak kayda alınır." \\
\hline
\end{tabular}


Finansal Kiralama İşlemlerinin Vergi Usul Kanunu ile Büyük ve Orta Boy İşletmeler( BOBİ) Açısından Karşılaştırılması Üzerine Bir Değerlendirme

\begin{tabular}{|c|c|c|}
\hline & $\begin{array}{l}\text { dönemlere ait faiz geliri olarak pasifleşti- } \\
\text { rilmek suretiyle değerlenerek kayıtlara } \\
\text { intikal ettirilecektir ( } 319 \text { nolu tebliğ). " }\end{array}$ & \\
\hline $\begin{array}{l}\text { Bilançoda Göste- } \\
\text { rim }\end{array}$ & $\begin{array}{l}\text { Bilanço dışı bırakılır ( } 319 \text { nolu teb- } \\
\text { liğ). }\end{array}$ & Bilanço dışı bırakılır (Bölüm 15.20) \\
\hline $\begin{array}{l}\text { Alacakların Takip } \\
\text { Yeri }\end{array}$ & $\begin{array}{l}120 \text { Alıcılar, } 121 \text { Alacak Senetleri, } \\
220 \text { Alıcılar, } 221 \text { Alacak Senetleri (11 } \\
\text { Sıra Nolu MSUGT) }\end{array}$ & $\begin{array}{l}\text { 136 Diğer Çeşitli Alacaklar, } 236 \text { Diğer Çe- } \\
\text { şitli Alacaklar }\end{array}$ \\
\hline Sonraki Ölçüm & $\begin{array}{l}\text { Faiz geliri ve Anapara Ödemeleri } \\
\text { olarak ayrıştırılır. } \\
\text { "Her bir dönem sonunda anapara geri } \\
\text { ödemelerinin düşülmesi sonucu kalan } \\
\text { tutar üzerinden sabit bir dönemsel faiz } \\
\text { oranı yaratacak şekilde hesaplanması su- } \\
\text { retiyle tahakkuk ettirilir (M.Madde } \\
\text { 290/2)" }\end{array}$ & $\begin{array}{l}\text { Alınan kira ödemeleri anapara geri öde- } \\
\text { mesi ve faiz geliri olarak ayrıştırılır. } \\
\text { "Finansman geliri kalan alacak tutarına sabit } \\
\text { bir faiz oranı uygulanacak Şekilde dönemlere } \\
\text { dağıtılır." }\end{array}$ \\
\hline $\begin{array}{l}\text { Kira ödemeleri ay- } \\
\text { rışması }\end{array}$ & $\begin{array}{l}\text { Kira ödemeleri, borç anapara öde- } \\
\text { mesi ve faiz gideri olarak ayrıştırılır. }\end{array}$ & $\begin{array}{l}\text { Kira ödemeleri ilk kayda almadan sonra } \\
\text { finansman gelirleri ve anapara geri öde- } \\
\text { mesi olarak ayrıştırılır. }\end{array}$ \\
\hline Faiz Oranı & $\begin{array}{l}\text { "Kira ödemeleri ile garanti edilmemiş } \\
\text { kalan değer toplamının bugünkü değe- } \\
\text { rini, kiralamaya konu iktisadî kıymetin } \\
\text { rayiç bedeline eşitleyen iskonto orant- } \\
\text { dır." }\end{array}$ & $\begin{array}{l}\text { "Kiralamadaki zımni faiz oranı: Kiralama } \\
\text { sözleşmesinin başlangıcında, kira ödemeleri- } \\
\text { nin bugünkü değeri ile garanti edilmemiş ka- } \\
\text { lıntı değerin bugünkü değerinin toplamını, ki- } \\
\text { ralanan varlığın gerçeğe uygun değeri ile ki- } \\
\text { raya verenin başlangıçta katlandığı doğrudan } \\
\text { maliyetlerin toplamına eşitleyen iskonto ora- } \\
\text { nıdır." }\end{array}$ \\
\hline $\begin{array}{l}\text { Kira ödemelerinin } \\
\text { bugünkü değeri }\end{array}$ & $\begin{array}{l}\text { "Kira ödemelerinin, sözleşme tarihinde, } \\
\text { kiralamada kullanılan faiz oranının dik- } \\
\text { kate alınması suretiyle hesaplanan bu- } \\
\text { günkü değerlerinin toplamıdır." }\end{array}$ & \\
\hline
\end{tabular}

\subsubsection{Kiralayana göre Finansal Kiralama İşlemlerininin BOBİ FRS ile VUK Açısından Karşılaştırılması}

\section{Tablo 3. Kiralayan Açısından Finansal Kiralama İşlemleri}

\begin{tabular}{|c|c|c|}
\hline & VUK & BOBİ FRS \\
\hline İlk Ölçüm & $\begin{array}{l}\text { "Borç, kiralama konusu iktisadî kıymetin } \\
\text { rayiç bedeli veya sözleşmeye göre yapılacak } \\
\text { kira ödemelerinin bugünkü değerinden dü- } \\
\text { şük olanıdır.(M.Madde 290/1)" }\end{array}$ & $\begin{array}{l}\text { "Borç, kiralanan varlı̆̆ın gerçeğe uygun değeri } \\
\text { ya } 103 \text { da kira ödemelerinin bugünkü değerin- } \\
\text { den düşük olanıdır.(BOBI FRS md. 15. 13)" }\end{array}$ \\
\hline $\begin{array}{l}\text { Aktife Alınacak } \\
\text { Hesap Grubu }\end{array}$ & $\begin{array}{l}\text { Maddi Olmayan Duran Varlıklar Gru- } \\
\text { buna } 260 \text { Haklar hesabına ( } 319 \text { Nolu } \\
\text { Tebliğ) }\end{array}$ & $\begin{array}{l}\text { İlgili duran varlık hesabında (BOBI FRS } \\
\text { md. 15. 14) }\end{array}$ \\
\hline $\begin{array}{l}\text { Amortisman } \\
\text { veya İtfa }\end{array}$ & $\begin{array}{l}\text { "Kullanım hakkı, Vergi Usul Kanunu ve il- } \\
\text { gili genel tebliğlerde bu iktisadi klymet için } \\
\text { tespit edilmiş amortisman sürelerinde } \\
\text { amorti edilecektir. ( } 319 \text { Nolu Tebliğ) Kira- } \\
\text { lama konusu iktisadi kıymet için belirlen- } \\
\text { miş esaslar çerçevesinde yeniden değerleme }\end{array}$ & $\begin{array}{l}\text { "Kiractnın kiralama süresi sonunda varlığın } \\
\text { sahipliğini elde edeceğine dair bir kesinlik } \\
\text { yoksa ilgili varlık kiralama süresi veya faydalı } \\
\text { ömürden kısa olanı itibarıla amortismana } \\
\text { veya itfaya tâbi tutulur. İlgili Duran Varlık } \\
\text { Grubunun tabi olduğu amortisman, itfa payı }\end{array}$ \\
\hline
\end{tabular}




\begin{tabular}{|c|c|c|}
\hline & $\begin{array}{l}\text { ve amortismana tabi tutulur } \\
\text { (M.Madde290.2)" }\end{array}$ & $\begin{array}{l}\text { ve değer düşüklü̈̆̈̈ uygulaması yapılır(BOBI } \\
\text { FRS md. 15. 18)" }\end{array}$ \\
\hline Sonraki Ölçüm & $\begin{array}{l}\text { "Kira ödemeleri, borç anapara ödemesi ve } \\
\text { faiz gideri olarak ayrıstırılır. Ayrıştırma iş- } \\
\text { lemi, her bir dönem sonunda kalan borç tu- } \\
\text { tarına sabit bir dönemsel faiz oranı uygu- } \\
\text { lanmasını sağlayacak şekilde yapılır. } \\
\text { (M.Madde 290/2)" }\end{array}$ & $\begin{array}{l}\text { "Finansman giderleri ve borç anapara ödemesi } \\
\text { olarak ayrıştırılır. Finansman giderleri kalan } \\
\text { borç tutarına sabit bir faiz oranı uygulanma- } \\
\text { sını sağlayacak şekilde kiralama süresi bo- } \\
\text { yunca her bir döneme dağıtılır. (md.15.17)" }\end{array}$ \\
\hline $\begin{array}{l}\text { Kira Borçlarının } \\
\text { Takip } \\
\text { yeri }\end{array}$ & $\begin{array}{l}301 \text { Finansal Kiralama İşlemlerinden } \\
\text { Borçlar, } \\
401 \text { Finansal Kiralama İşlemlerinden } \\
\text { Borçlar (11 SERİ NO'LU MUHASEBE } \\
\text { SISTEMİ UYGULAMA GENEL TEB- } \\
\text { LİĞİ) }\end{array}$ & $\begin{array}{l}301 \text { Finansal Kiralama İşlemlerinden Borç- } \\
\text { lar, } \\
401 \text { Finansal Kiralama İşlemlerinden Borç- } \\
\text { lar }\end{array}$ \\
\hline $\begin{array}{l}\text { Kira Faizlerinin } \\
\text { Takip Yeri }\end{array}$ & $\begin{array}{l}302 \text { Ertelenmiş Finansal Kiralama Borç- } \\
\text { lanma Maliyeti, } \\
402 \text { Ertelenmiş Finansal Kiralama Borç- } \\
\text { lanma Maliyeti (11 Seri No'lu Muha- } \\
\text { sebe Sistemi Uygulama Genel Tebliği) }\end{array}$ & $\begin{array}{l}302 \text { Ertelenmiş Finansal Kiralama Borç- } \\
\text { lanma Maliyeti, } \\
402 \text { Ertelenmiş Finansal Kiralama Borç- } \\
\text { lanma Maliyeti }\end{array}$ \\
\hline $\begin{array}{l}\text { Kira Ödeme ay- } \\
\text { ristırma }\end{array}$ & $\begin{array}{l}\text { "Kira ödemeleri, borç anapara ödemesi ve } \\
\text { faiz gideri olarak ayrı̧stırılır. Ayrıştırma iş- } \\
\text { lemi, her bir dönem sonunda kalan borç tu- } \\
\text { tarına sabit bir dönemsel faiz oranı uygu- } \\
\text { lanmasını sağlayacak şekilde yapılır." }\end{array}$ & $\begin{array}{l}\text { "Kira ödemeleri ilk kayda almadan sonra fi- } \\
\text { nansman giderleri ve borç anapara ödemesi } \\
\text { olarak ayrıstırılır. Finansman giderleri kalan } \\
\text { borç tutarına sabit bir faiz oranı uygulanma- } \\
\text { sını sağlayacak şekilde kiralama süresi bo- } \\
\text { yunca her bir döneme dağıtılır. Şarta bağlı kira } \\
\text { ödemeleri ise oluştukları dönemde kâr veya za- } \\
\text { rara yansıtılır." }\end{array}$ \\
\hline
\end{tabular}

\section{Uygulama}

Şirket inşaat faaliyetlerinde kullanılmak üzere finansal kiralama yoluyla bir kule vinç kiralamak istemektedir. Kiralanmak istenen Kule Vinç'in piyasa değeri 500.000 £'dir. Şirket kule vinç bedelini 5 yılda eşit taksitler üzerinden banka aracılığıyla ödeyecektir. Varlık finansal kiralama yolu yerine borçlanarak satın alınsaydı borçlanma faizi yıllık \%10 olacaktı. Kule Vinç'in V.U.K.'na göre faydalı ömrü 10 yıldır. Varlığın hurda değeri 50.000 TL olup, varlığın sözleşme sonunda kiracı tarafından alınacağına dair bir anlaşma bulunmamaktadır. Ayrıca kiralama işlemi ile ilgili 5.000 TL masraf kiracı tarafından peşin olarak ödenmiştir. (KDV \%18 ve hariçtir.)

Çözüm: Öncelikle 5 yıllık süre boyunca ödenecek taksit tutarlarının belirlenmesi gerekmektedir. Varlığın gerçeğe uygun değeri 500.000 £'dir. 
Kiracı için 5.yılın sonundaki varlığın hurda değerinin bugünkü değerinin hesaplanması gerekmektedir.

$$
\begin{aligned}
& \text { Bugünkü değer }=\text { Piyasa Değeri }-\frac{\text { Gelecekteki değer }}{(1+\text { iskonto orant) })^{\text {süre }}} \\
& \text { Bugünkü değer }=500.000 \mathrm{TL}-\frac{50.000 \mathrm{TL}}{(1+0,10)^{5}} \\
& \text { Bugünkü değer }=468.953,90 \risingdotseq
\end{aligned}
$$

Varlığın bugünkü değeri 468.953,90 £ dir. Kira ödemelerinin tutarları hesaplanırken aşağıdaki formülden faydalanılacaktır.

A: Anapara, i: Faiz Oranı, n: Vade

Axi

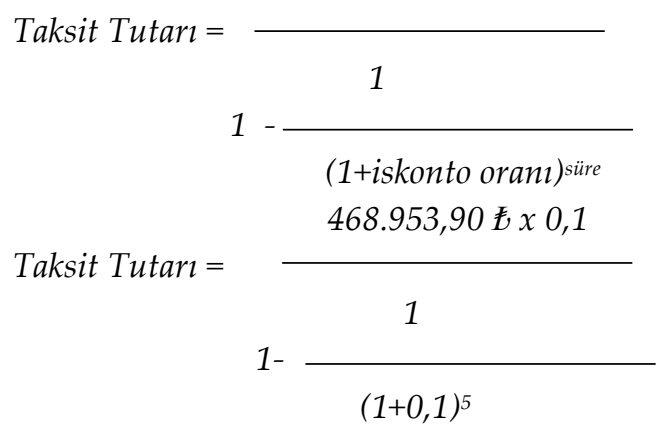

Taksit Tutarn $=123.708,87 £$

Yıllık ödenecek kira tutarı 123.708,87 £ olarak hesaplanmıştır. İşletme 5 yıl boyunca aynı tutarı ödeyecektir ve dördüncü yılın sonunda varlığın hurda değeri 50.000 £ olacaktır. Hesaplamaya göre varlığın işletmeye maliyeti $(5 \times 123.708,87 £)+50.000 \mathrm{TL}=668.554,34$ £'ye mal olacaktır.

Birinci yıl için işletmenin ödeyeceği faiz tutarı 500.000 x \% $10^{\prime}$ ten 50.000 €'dir. Buna göre işletmenin birinci yılda ödeyeceği 123.708,87 €́nin 50.000 €’si faiz, 73.708,87€anapara ödemesidir. İkinci yıl faiz kalan anapara üzerinden hesaplanacaktır. İkinci yılın faizi 426.291,13 £ x \%10 den 42.629,11 £'dir.Varlığın değeri ile ilgili tüm ödeme planı aşağıdaki tabloda gösterilmiştir 
Tablo 4. Finansal Kiralama Ödeme Planı

\begin{tabular}{|c|c|c|c|c|c|}
\hline \multirow{2}{*}{$\begin{array}{c}\text { Y1llık Faiz } \\
\text { Tarih }\end{array}$} & \multirow{2}{*}{$\begin{array}{c}\% 10 \\
\text { Dönem }\end{array}$} & \multicolumn{2}{|c|}{ Finansal Kiralama Tutarı } & \multirow[b]{2}{*}{ Anapara } & \multirow[b]{2}{*}{ Kalan Anapara } \\
\hline & & Kira Tutarı & Faiz & & \\
\hline 1. YIL & & & & & $500.000,00 €$ \\
\hline 1. YIL & 1. Taksit & $123.708,87 €$ & $50.000,00 €$ & $73.708,87 €$ & $426.291,13$ € \\
\hline 2. YIL & 2. Taksit & $123.708,87 €$ & $42.629,11 €$ & $81.079,75 €$ & $345.211,38 €$ \\
\hline 3. YIL & 3. Taksit & $123.708,87 €$ & $34.521,14 €$ & $89.187,73 €$ & $256.023,65 €$ \\
\hline 4. YIL & 4. Taksit & $123.708,87 €$ & $25.602,36 €$ & $98.106,50 €$ & $157.917,14 €$ \\
\hline 5. YIL & 5. Taksit & $123.708,87 €$ & $15.791,71 €$ & $107.917,15 €$ & 49.999,99£ \\
\hline 5. YIL & Hurda & $50.000,00 €$ & $0,00 €$ & $50.000,00 €$ & $0,00 €$ \\
\hline & & $668.544,34$ モ & $168.544,33 €$ & $500.000,01 €$ & \\
\hline
\end{tabular}

\subsection{Finansal Kiralama İşlemlerinin Kiracı Tarafından Mu- hasebeleştirilmesi}

4.1.1. Vergi Usul Kanunu'a göre ilk kayıt, birinci taksit ödemesi ve amortisman kaydı

\begin{tabular}{|c|c|c|c|c|}
\hline & & & Borç & Alacak \\
\hline 1 & $\begin{array}{ll}260 & \text { HAKLAR } \\
302 & \text { ERT.KİR.BORÇ.MAL. } \\
402 & \text { ERT.Kİ.BORÇ.MAL. } \\
770 & \text { GENEL YÖNETIM GİDEI }\end{array}$ & 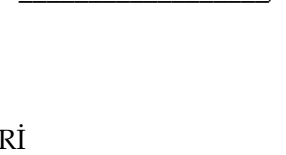 & $\begin{array}{r}500.000,00 € \\
50.000,00 € \\
118.544,00 € \\
5.000,00 €\end{array}$ & \\
\hline & $\begin{array}{rr}100 \\
& 301 \\
& 401\end{array}$ & $\begin{array}{l}\text { KASA } \\
\text { FIN.KİR.İŞL.BORÇ } \\
\text { FIN.KİR.IŞL.BORÇ }\end{array}$ & & $\begin{array}{r}5.000,00 € \\
123.708,87 € \\
544.835,47 €\end{array}$ \\
\hline 2 & $\begin{array}{l}301 \text { FİN.KİR.İSL.BORÇ } \\
191 \text { İNDİRİECEK KDV } \\
\\
\text { 1. Taksit Ödeme Kayd } 102\end{array}$ & BANKALAR & $\begin{array}{r}123.708,87 € \\
22.267,60 €\end{array}$ & 145.976,46£ \\
\hline 3 & $\begin{array}{l}780 \text { FINANSMAN GID. } \\
302 \\
\text { Finansman Gideri Kayd } 1\end{array}$ & ERT.KİR.BORÇ.MAL. & 50.000,00 € & $50.000,00 €$ \\
\hline 4 & $\begin{array}{l}730 \text { GENEL ÜRETIM GIDERI } \\
268 \\
\text { 1. Y1l Amortisman Kaydı }\end{array}$ & BİRK. AMORT. & $45.000,00 €$ & $45.000,00 €$ \\
\hline
\end{tabular}




\subsubsection{Bobi FRS'ye göre ilk kayıt, birinci taksit ödemesi ve amortisman kaydı}

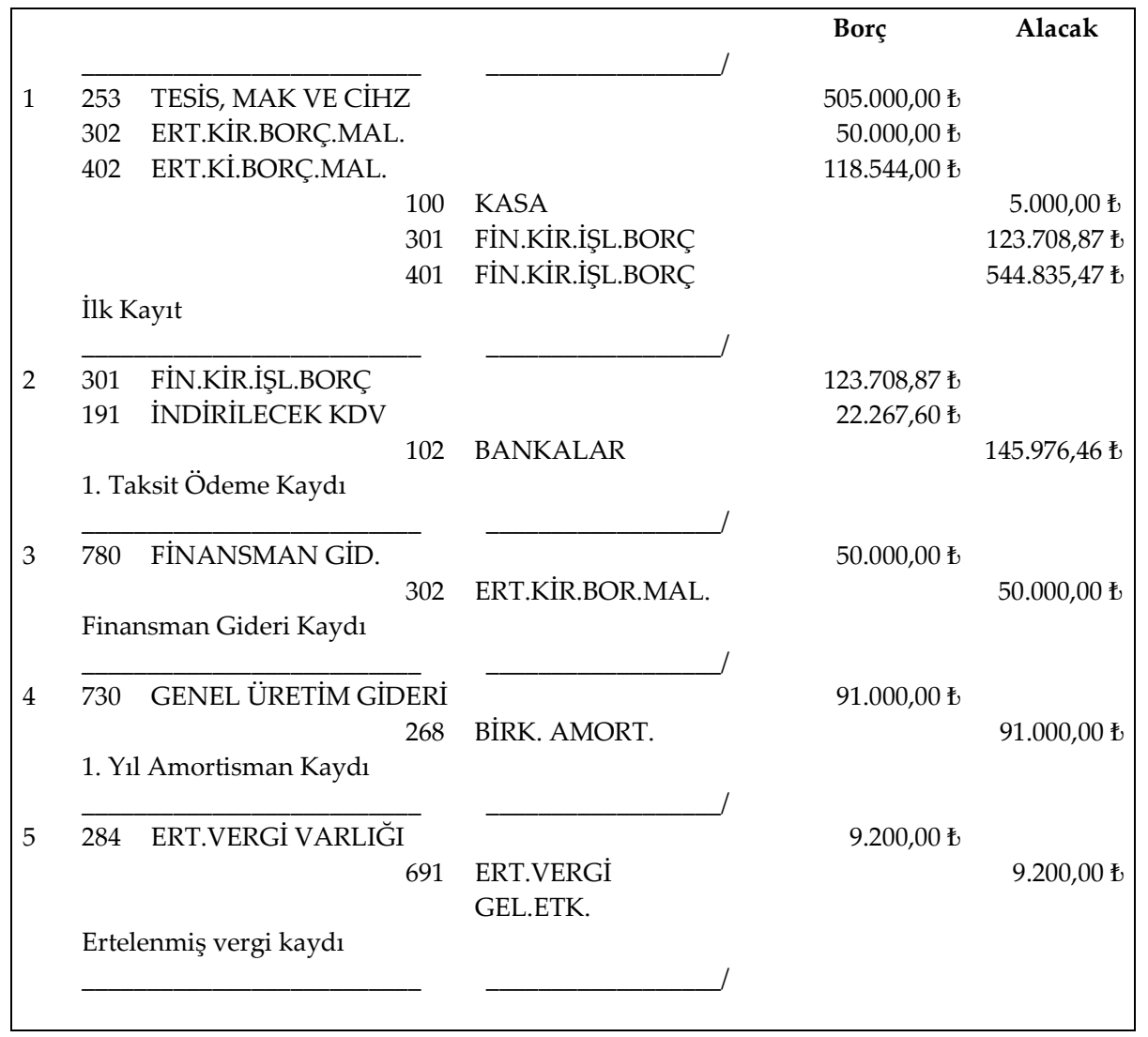

\section{Sonuç ve Öneriler}

Finansal kiralama işlemleri ülkemizde değişen ekonomi metodları ile birlikte sıklıkla gerçekleştirilir hale gelmiştir. Finansal kiralama işlemlerine ait mevzuat bilgilerinin hem kiralayan hem de kiraya veren tarafından bilinmesi, işletmeler için önemli rol alan finansal tabloların güvenirliği için önemlidir. Finansal kiralama işlemleri için farklı mevzuat bilgileri mevcuttur. Yapılan bu araştırmada finansal kiralama işlemleri ile ilgili 
Vergi Usul Kanunu ve BOBİ FRS arasındaki kiralayan ve kiracı açısından benzerlikler ile farklılıklar irdelenmiştir ve tablolar halinde belirtilmiştir.

Kiralama işlemi yapıldığında, kiracının maddi duran varlıklara mı yoksa maddi olmayan duran varlığın mı kaydedeceği konusu farklardan biridir. MSUGT bunu maddi olmayan duran varlıklarda raporlarken, BOBİ FRS ilgili maddi duran varlık hesabına aktarılmasını önermektedir. Kiraya veren açısından ise VUK yapılan işlemi ticari alacaklar grubunda raporlarken, BOBİ FRS kira tutarlarını diğer alacaklar grubunda izlemektedir. Çalışmada belirtildiği gibi finansal kiralama işleminde kiraya veren açısından yapılan çalışmalarda farklı muhasebeleştirme örnekleri gözlemlenmiştir. Yukarıda belirtilen hususlarda görüldüğü üzere uygulamalar arasında farklılıklar bulunmaktadır. Bu farklılıkların giderilmesi muhasebede tek düzelik ve tutarlılık açısından uygun olacaktır. 


\title{
EXTENDED ABSTRACT
}

\section{An Assessment on the Comparison of Financial Leasing with The Tax Procedural Law and The Financial Reporting Standards for Large and Medium-Sized Enterprises}

\author{
Murat Karahan \\ Gaziantep University
}

In Turkey, leasing, large and medium-sized enterprises, is one of the methods for providing the financing required for business operations and execution is increasing every year. Therefore, the issue of financial leasing should be better investigated by taxpayers. However, it is important to identify all the positive and negative aspects of financial leasing in order to maximize the profits of enterprises.

History of financial leasing Going back to the 2000s, then Leasing was started to be used by businesses in the United States in the 1930s and in Europe in the 1960s. The history of financial leasing in Turkey is based on the 1983.

Leases are classified as operating leases and finance leases. Therefore, different accounting approaches result in accounting and reporting of a financial event in different ways and hence, leasing transactions are not shown as reliable in the financial statements. As a result, users of financial statements are not able to obtain information that is understandable, reliable, comparable and appropriate. In order to prevent these situations, standard setters have done some work in order to improve the accounting of leasing.

According to the European Leasing Association, "Financial Leasing is defined as an agreement that leases the right of ownership of the movable or immovable purchased by the lessee and purchased by the lessor for a certain period of time and leaves the right of use to the lessee". According to the Law No. 6361 on Leasing, Factoring and Financing Companies "Financial Leasing can be defined as the transfer of ownership of a property to the lessee at the end of the lease period in order to obtain financing from the lessor authorized by the law or the relevant legislation, on a contractual basis; granting the lessee the right to purchase the good at a fair value at the end of the lease term; leasing process which provides a period of greater than eighty percent of the 
economic life of the property or if the total value of the present value of the lease payments to be made under the leasing agreement is greater than ninety percent of the fair value of the asset".

With today's conditions gaining an international dimension; International Financial Reporting Standards (IFRS) have been implemented in our country in order to eliminate the problems faced by the companies that gained international dimension due to different applications in different countries and to achieve transparency and comparability in financial statements. The Public Oversight Accounting and Auditing Standards Authority (POA) is the only authority authorized to publish these standards. Conflicts between tax laws and accounting practices as well as published standards arise in financial leasing transactions.

Today, the tendency to alternative sources of financing is important for enterprises in increasingly emerging economies. One of the preferred methods of finance as a source of enterprises is financial leasing which has been used in the world for a long time and settled in our country. In accordance with Turkey Accounting Standard 17 (IAS 17 Leases Standard) by leasing; It is the contract to which all the risks and benefits arising from owning an asset are transferred. The continuity of the changes in the legal regulations has caused changes in terms of both the lessor and the tenant in the financial leasing transactions. In this context, the aim of this study is to make a comparative study on the legislative changes made in recent years in terms of financial leasing in Large and Medium-sized Enterprises, especially in the Tax Procedure Law (TPL), Financial Reporting Standard for Large and Medium-Sized Enterprises (LMS FRS), and LMS FRS to identify similarities and differences from the parties opener. The general comparison of financial leasing transactions is given in Table 1.

Table 1. General comparison of financial leasing transactions

\begin{tabular}{|l|l|l|}
\hline & Tax Procedure Law & $\begin{array}{l}\text { Financial Reporting Standard for } \\
\text { Large and Medium Sized Enterprises }\end{array}$ \\
\hline $\begin{array}{l}\text { Financial Leasing - Operating Le- } \\
\text { ase Distinction }\end{array}$ & None & None \\
\hline $\begin{array}{l}\text { Operating Leases Where to be re- } \\
\text { corded }\end{array}$ & - & - \\
\hline $\begin{array}{l}\text { Amendment to the Contract } \\
\text { Amendments }\end{array}$ & - & - \\
\hline Initial direct costs & $\begin{array}{l}\text { Written as term } \\
\text { expense. }\end{array}$ & Initial direct costs are added to the cost. \\
\hline
\end{tabular}


In this study, the similarities and differences between the Tax Procedures Law and BOBİ FRS regarding leasing and tenants are examined and stated in tables. When leasing is performed, it is one of the differences that reveal whether the lessee will record tangible assets or intangible assets. MSUGT bunu maddi olmayan duran varlıklarda raporlarken, BOBİ FRS ilgili maddi duran varlık hesabına aktarılmasını önermektedir. Kiraya veren açısından ise VUK yapılan işlemi ticari alacaklar grubunda raporlarken, BOBİ FRS kira tutarlarını diğer alacaklar grubunda izlemektedir.

As stated in the study, different accounting examples have been observed in the studies carried out in terms of the lessor in the leasing transaction. As seen above, there are differences between the applications. Elimination of these differences will be appropriate in terms of uniformity and consistency in accounting.

\section{Kaynakça / References}

Acar, M., Temiz, H., ve Aktaş, R. (2017). UMS 17 kiralama işlemleri standardından UFRS 16'ya geçişin finansal tablolar üzerinde etkisi: Borsa İstanbul örneği. Muhasebe Bilim Dünyası Dergisi, 19(3), 592-623.

Akbulut, D. H. (2018). Faaliyet kiralaması işlemlerinin aktifleştirilmesinin finansal tablolara ve finansal oranlara etkisi üzerine bir telekomünikasyon şirketinin vak'a incelemesi. Muhasebe ve Finansman Dergisi, 78, 17-36.

Aslan, Ü. (2018). UFRS 16 kiralamalar standardı kapsamında faaliyet kiralamasının kiracı işletme tarafından muhasebeleştirilmesi ve raporlanmas1. Muhasebe ve Finansman Dergisi, (77), 55-68.

Cengiz, S. (2017). Finansal kiralama işlemlerinin mevzuat boyutu ve muhasebe uygulamaları: TMS 17 ve VUK kapsaminda incelenmesi. Küresel İktisat ve İşletme Çalışmaları Dergisi, 6(11), 43-56.

Demirci, Ş. D., ve Kıymaz Kıvraklar, M. (2018). Ulusal ve uluslararası düzenlemeler çerçevesinde finansal kiralama işlemlerinin muhasebeleştirilmesi. Muhasebe ve Vergi Uygulamaları Dergisi (Özel Say1), 508-531.

Doldur, S. (2018). Finansal kiralama işlemlerinde değerleme, muhasebe kayıtları ve bazı özellikli durumlar. Mali Çözüm, (145), 225-249. 
Duman, H., Polat, Y., ve Yücenursen, M. (2015). Türkiye muhasebe standartları (TMS) 17'ye göre finansal kiralamanın finansal tablolar ve oranlar üzerine etkisi. Journal of Social and Humanities Sciences Research, $5(1), 1-28$.

Gökgöz, A. (2013). Finansal kiralama işlemlerinin muhasebeleştirilmesi. Dumlupınar Üniversitesi Sosyal Bilimler Dergisi, (35), 107-121.

Gönen, S., \& Akça, N. (2014). Finansal kiralama işlemlerinin TMS 17 kiralama işlemleri standardı ve vergi usul kanunu açısından muhasebeleştirilmesi. Muhasebe ve Finansman Dergisi, (64), 71-94.

Kamu Gözetim Kurumu. (2017). Büyük ve orta boy işletmeler için finansal raporlama standard1. T.C. Resmi Gazete: 30138 .

Kayapınar, A., ve Eflatun, A. O. (2017). Büyük ve orta boy işletmeler için finansal raporlama standard uygulamalar ve yorumları. Ankara: Gazi Kitapevi.

Kırlıŏ̆lu, H., ve Öztaş, S. (2015). Türkiye'de finansal kiralama işlemleri ve muhasebeleştirilmesi. Journal of Accounting, Finance and Auditing Studies, 1(2), 1-21.

Köksal, A. G., ve Beller, B. (2013). Finansal kiralama işlemlerinin TMS 17, vergi mevzuatı, BDDK tebliği açısından incelenmesi ve muhasebe uygulamaları. Niğde Üniversitesi İIBF Dergisi, 6(2), 150-171.

Maliye Bakanlığı. (2003). 11 seri no'lu muhasebe sistemi uygulama genel tebliği. T.C. Resmi Gazete: 25185 .

Marşap, B., ve Yanık, S. (2018). IFRS 16 kapsamında kiralama işlemlerinin finansal raporlamaya etkisinin incelenmesi. Muhasebe ve Finansman Dergisi, (80), 23-42.

Öztürk, C. (2016). UFRS 16 kiralama işlemleri standardının eski UMS 17 standardı ile karşılaştırılması ve Almanya ve Türkiye'de hisse senetleri halka açık olan hava yolu şirketlerinin finansal durumuna etkisi. Muhasebe Bilim Dünyası Dergisi, 18(1), 1-50.

Pamukçu, F., ve Çakmak, M. (2017). Uluslararası ticarette finansal kiralama işlemleri ve muhasebeleştirilmesi. Marmara Üniversitesi Öneri Dergisi, 12(48), 245-267.

Şeker, K., ve Çemberlitaş, İ. (2018). TMS 17 kapsamında finansal kiralama işlemlerinin raporlanması. Sosyal Bilimler Akademi Dergisi, 1(1), 42-60.

Şengür, E. D. (2013). Finansal kiralama işlemlerinde kiracı açısından asgari kira ödemelerinin hesaplanması ve finansal raporlama üzerindeki etkileri. Niğde Üniversitesi İIBF Dergisi, 6(1), 263-279. 
Şentürk, F. (2016). Türk Vergi Mevzuatı kapsamında faaliyet kiralaması yapan işletmelerde muhasebe uygulamaları. Journal of Business Research-Türk, 8(1), 619-639.

Şenyiğit, Y. B. (2014). Finansal kiralama işlemlerinin muhasebeleştirilmesinde ve raporlanmasında beklenen değişiklikler: Bir hava yolu işletmesinde vak'a çalışması. Ç.Ü. Sosyal Bilimler Enstitüsü Dergisi, 23(1), 288-299.

Şişman, D., ve Şişman, M. (2017). Finansal kiralama (leasing) ve ekonomi için önemi: Riskler, avantajlar. Yönetim ve Ekonomi Araştırmaları Dergisi (Özel Sayı 1), 144-154.

T.C. Kırşehir Valiliği Defterdarlık Gelir Müdürlüğü. (2011). Özelge: Finansal kiralama işleminden sonra oluşan ana para kur farkları ile faizlerin ilk y1l iktisadi kıymetin maliyetine eklenmesi, sonraki ylllar ise gider veya maliyet olarak dikkate alınması hk. Sayı: B.07.4.DEF.0.40.10.00008-19.

Wyman, H. E. (1973). Financial lease evaluation under conditions of uncertainty. The Accounting Review, 48(3), 489-493.

Yakut, M. (2016). Finansal kiralama işlemlerinin türkiye muhasebe standardı 17 kiralama işlemleri ve vergi mevzuatı açısından değerlendirilmesi ve muhasebeleştirilmesi. Muhasebe ve Denetim Dünyası, 1(2), 95-122.

Yardımcıoğlu, M. (2016). İcare (Finansal Kiralama) işlemlerinin islami muhasebe standartları çerçevesinde incelenmesi. Journal of Social and Humanities Sciences Research, 6(2), 62-77.

Yıldız, F., Kara, E.,ve Yanık, A. (2014). KOBI TFRS'ye göre kiralama işlemlerinin muhasebeleştirilmesi. AÏBÜ Sosyal Bilimler Enstitüsü Dergisi, 14(1), 461-478.

\section{Kaynakça Bilgisi / Citation Information}

Karahan, M. (2019). Finansal kiralama işlemlerinin vergi usul kanunu ile büyük ve orta boy işletmeler( BOBİ) açısından karşılaştırılması üzerine bir değerlendirme. OPUS-Uluslararası Toplum Araştırmalarl Dergisi, 13(19), 2259-2285. DOI: 10.26466/opus.568710 